\title{
Towards a Sri Lankan National Trauma System
}

\author{
Fitzgerald $\mathbf{M} \mathbf{C}^{1,2,3}$, O'Reilly $\mathbf{G} \mathbf{M}^{1,3,4}$, Seneviratne $\mathbf{R}^{5}$, Ellawala $\mathbf{R}^{6}$, Cameron $\mathbf{P} \mathbf{A}^{1,3,4}$ \\ Journal of the Ceylon College of Physicians, 2017, 48, 24-25
}

Death and disability from road crashes is a profound global burden, with substantial personal and economic costs. It is the commonest cause of death for those aged between 15 and 29. In Sri Lanka, for example, physical injury (trauma) is the leading cause of hospitalization, with deaths from road crashes, almost doubling from 1,937 in 2003 to 3,691 in $2013^{1,2}$.

Road deaths represent a small fraction of the total injury burden, with significant short and long term resources required by the severely injured survivors. Road deaths are a significant and measurable proportion of the total injury burden. Medical interventions which reduce road trauma morbidity and mortality also reduce the overall burden of injury.

In March 2010, the United Nations General Assembly proclaimed the Decade of Action for Road Safety 2011-2020, which recognized the enormity of the current trauma epidemic. The United Nations aimed to reduce global road traffic deaths and injuries by $50 \%$ by $2020^{3}$.

Almost simultaneously in 2010 , in response to an increasing national injury burden, the Non-Communicable Diseases Unit of the Ministry of Health, Sri Lanka released the National Policy and Strategic Framework on Injury Prevention and Management in Sri Lanka ${ }^{4}$.

This policy was a further development of the preexisting goal of the National Trauma Secretariat of Sri

\footnotetext{
${ }^{1}$ Trauma Service, The Alfred, Melbourne, Australia.

${ }^{2}$ National Trauma Research Institute, Melbourne, Australia.

${ }^{3}$ Emergency and Trauma Centre, The Alfred, Melbourne, Australia.

${ }^{4}$ School of Public Health and Preventive Medicine, Monash University, Melbourne, Australia.

${ }^{5}$ Teaching Hospital Karapitiya, Galle, Sri Lanka.

${ }^{6}$ Sir John Kotelawala Defence University, Colombo, Sri Lanka.
}

Corresponding author: Fitzgerald MC, E-mail: m.fitzgerald@alfed.org.au
Lanka - that timely, appropriate, quality and cost-effective medical care is provided to trauma victims by a coordinated, sustainable trauma system. A Trauma System is an integrated and systematic structure which provides optimal care to injured patients from onset of injury through rehabilitation to the return of ideal functioning. The main objective of an established Trauma System is to get the right patient to the right hospital in the right amount of time whilst receiving the right care ${ }^{5}$.

The goal of a $50 \%$ reduction in road deaths may have seemed overly ambitious, but this reduction had been achieved at regional levels with the introduction of inclusive, integrated Trauma Systems over a similar time period of 10 years ${ }^{6,7,8}$.

However, now more than half way through the Decade of Action there had been little evidence of a decline in road deaths globally or in Sri Lanka ${ }^{9}$. There are clearly multiple reasons for the continued increase in road trauma in Sri Lanka, including gaps in the provision of public transport, an increase in road networks with quality surfaces (allowing increased speed), a corresponding increase in the density of road traffic and a lack of progress in improving driver behaviour. The impact of these causes of increased road collisions along with an increased severity of injury - is further compounded by a still under-developed post-crash prehospital and hospital trauma system.

To reduce this ever-increasing injury toll, a systematic approach to implementation of the multiple potential pre-crash and post-crash interventionsis required. Importantly, and as highlighted in the World Health Organization document, ' ... the gross disparities in injury outcomes between high-income countries and low- and middle-income countries relate directly to the level of care received immediately post-crash ... and later in a healthcare facility'.

The development of regional Trauma Systems is essential for improving outcomes of the injured ${ }^{10}$. The improvement in post-crash medical care and the associated mortality reduction is an immediate result following the establishment of integrated, inclusive trauma systems.

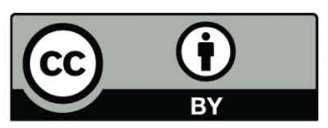

This is an open-access article distributed under the terms of the Creative Commons Attribution License, which permits unrestricted use, distribution, and reproduction in any medium, provided the original author and source are credited. 
Accordingly, the implementation of the long held goal of the National Trauma Secretariat - the development of an integrated Sri Lanka National Trauma System - has now become a matter of urgency.

\section{References}

1. www.roadinjuries.globalburdenofinjuries.org/sri-lanka accessed 30 January 2017.

2. www.transport.gov.lk/web accessed 30 January 2017

3. http://www.who.int/roadsafety/decade_of_action/en/ accessed 30 January 2017.

4. http://203.94.76.60/nihs/English(NPIM).pdf accessed 30 January 2017.

5. https://www.aci.health.nsw.gov.au/get-involved/institute- of-trauma-and-injury-management/clinical/trauma_system accessed 30 January 2017

6. http://www.c4ts.qmul.ac.uk/main/latest-news/post/21Iondons-trauma-system-dramatically-reduces-mortality-rates accesses 30 January 2017 accessed 30 January 2017.

7. Atkin C, Freedman I, Rosenfeld JV, Fitzgerald M, Kossmann $\mathrm{T}$, et al. The evolution of an integrated state trauma systems in Victoria, Australia. Injury 2005; 36: 1277-87.

8. Cameron PA, Gabbe B, Cooper DJ, Walker A, Judson R, McNeil. A statewide system of trauma care in Victoria: effect on patient survival. Med J Aust 2008; 189: 546-50.

9. http://www.who.int/violence_injury_prevention/road_safety_ status/2015/en/ accessed 30 January 2017.

10. Fitzgerald M, Dewan Y, O'Reilly, Matthew J, McKenna C. India and the Management of Road Crashes: Towards a National Trauma System. Indian J Surg, Aug 2006; 68(4): 237-43. 